\title{
Foundation with increased load bearing base capacity
}

\author{
Nikolay Sokolov ${ }^{1,2}{ }^{*}[0000-0001-6729-7003]$, Boris Mikhailov ${ }^{1}$ [0000-0001-6511-6985], \\ and Svetlana Viktorova ${ }^{10000-0002-9056-4410]}$ \\ ${ }^{1}$ Chuvash State University named after I.N. Ulyanov, 428015, prosp. Moskovsky, Cheboksary, \\ Russia \\ ${ }^{2}$ LLC NPF FORST, 428000, Kalinin st., Cheboksary, Russia
}

\begin{abstract}
Along with other advanced geotechnical technologies for the exploration of underground space, electro-discharge technology (EDT technology) is one of the fundamental in the field of the construction of auger-injection microcircuits, as well as the construction transformation of the properties of foundation soils with weak physical and mechanical characteristics. At the same time, having significant differences compared to other methods of subsurface development of buildings and structures, the geotechnical EDT technology has a number of advantages, such as: 1) increased specific soil load-bearing capacity; 2) constructability of the auger piles in any geotechnical conditions; 3 ) possibility of geotechnical works performance under restricted conditions. As a basic structure for the development of new technologies, it has a large scientific research potential for the purposes of introducing it into modern underground construction.
\end{abstract}

Keywords: Carrying capacity, Drilling pile, Pile cap, EDT piles, Multi-seater extensions, Injections.

\section{Introduction}

The use of bases and foundations of increased bearing capacity is a topical task of modern geotechnical construction. Of all the existing foundation technologies, buried structures such as large diameter drill piles are the most in demand. The existing technologies of the arrangement of these piles allow achieving significant values of bearing capacity $F_{d}$. At the same time, it can be increased only by changing their length and diameter. An alternative to auger piles for high $F_{d}$ values is electric-discharge piles (EDT piles). The expansion along the EDT pile may increase its bearing capacity. At that, each additional increase significantly increases $F_{d}$. Thus, by controlling the number of thickenings depending on stratification of geotechnical elements of the construction site, it is possible to achieve the required values of carrying capacity of EDT piles.

\section{Materials and methods}

The electro-discharge technology, having a number of technical and technological advantages, is widely used in geotechnical practice for the construction of EDT drilling

\footnotetext{
*Corresponding author: ns sokolov@mail.ru
} 
piles in piling fields, piles for reinforcement of bases and foundations, fixing of foundations, slopes, when constructing nagels, etc. The technological advantage of this system is the explosive conversion of electrical energy into mechanical energy. The invention makes it possible to convert the electrical energy into mechanical energy. The electro-hydraulic shock energy density reaches $150 \mathrm{~J} / \mathrm{m}^{3}$ in a very short time (fraction of microseconds). The electro-hydraulic impact on the ground of the borehole wall filled with fine-grained concrete corresponds to a static load of up to $200.0 \mathrm{kPa}$. As a result of these high pressures and temperatures, a cavity is formed in the ground by gravitational forces, which are filled with fine-grained concrete. In this way there is an increase on a specific section on the height of the EDT-pile. This enlargement is further called «thrust bearing». In this way an additional support is created, which statically works together with the EDTpile on the lower surface of the expansion and increases the load capacity of the EDT-pile on the ground. The geometrical parameters of the shape of the expansion in the first approximation can be taken as a sphere. The parameters of the sphere, such as diameter and height $\boldsymbol{h}$, depend on electro-hydraulic impact energy, porosity, humidity and the type of soil to be treated. The diameter of the increase $\boldsymbol{D}$ can be determined by the size of the maximum decrease of the level of fine-grained concrete in the well, as geo-technics say, by «losses». It should be noted, of course, that the values of «the losses» during electrohydraulic treatment (that is why the level of fine-grained concrete should always be kept on the ground surface) and vary considerably over time. «The losses» in time from the beginning of concrete laying to the beginning of concrete hardening can be from several centimetres to several meters. First of all, such large decreases are related to the specificity of the soil as a porous material. These vertical movements of fine concrete are further increased by electroosmotic absorption of cement milk into its soil structure.

\section{Results and discussion}

In modern geotechnical construction there are technologies for construction of foundations of increased bearing capacity. In accordance with the normative document TSN-306-2005 «Bases and foundations of increased load-bearing capacity», approved by the order of the Ministry of construction, architecture and housing of the Rostov region dated 28.04.2005 № 59, provisions are established to improve the building properties substructures of buildings and structures by means of injection of chemical solutions, reinforcement of the foundation through directional hydraulic fractures, and reinforcement with injection piles and auger-filled elements. Chemical injections are only relevant for structurally unstable soils. Therefore, in modern geotechnical construction there is a wide demand for auger piles.

The construction of the underground part of any structure requires the special attention of [1-9] geologists. Any introduction of structural elements into the base, as well as extraction of soil from it, alters the stress-strain state of the base (SSS) that has developed over a long geological period. Also, extraction of soil from it leads to its decomposition. At the same time, the larger the diameter of the working part of the drilling rig, the greater the negative impact on the base as a consequence of the excavated soil. In order to minimize the adverse effects in order to restore the existing SSS in drilling piles, it is necessary to use technologies that contribute to the restoration of the substrate structure.

Design organizations, as a rule, with loads on piles, most often design bored piles with a diameter of $600.0 \mathrm{~mm}$ and more.

Almost any civil engineer knows that the larger the pile diameter, the greater its bearing capacity. A bored pile of any diameter can be assigned. But the main criterion for the final designation of the type (diameter and length) of a bored pile is, in addition to technical feasibility, also economic efficiency. 
The investor always invests money in the most economical, and at the same time, reliable type of foundation. Thus, for the case of the pile foundation, economic efficiency is considered together with the cost of the pile field and pile caps [10-14].

For proof of the above, the following are excerpts showing the advantages of bored injection piles made using electro-discharge technology (EDT piles), as compared to drill piles.

Determination of bearing capacity $F_{d}$ is made according to the formula (7.11) SP 24.13330.2011 «Pile foundations»:

$$
F_{d}=\gamma_{c}\left(\gamma_{c R} R A+\gamma_{c f} u \Sigma f_{i} h_{i}\right)
$$

where $\gamma_{c}$ - is the soil pile operating condition assumed to be $1 ; R$-is the design soil resistance below the bottom end of the pile, $\mathrm{kPa}$, taken from SP 24.13330.2011, Table 7.2; $A$ - is the pile foundation area $\left(\mathrm{m}^{2}\right) ; u$ - external perimeter of pile cross section, $\mathrm{m}$; fi is the design resistance of the $\mathrm{i}$-th soil layer on the side surface of the pile, $\mathrm{kPa}\left(\mathrm{tf} / \mathrm{m}^{2}\right)$, taken from Table 7.3 SP 24.13330.2011; hi - is thickness of the $i$-th layer of soil contacting the pile lateral surface, $\mathrm{m} ; \gamma_{c f}-$ is the coefficient of soil conditions, respectively, under the bottom end and on the side surface of the pile, which takes into account the effect of the pile sinking method on the values of the calculated soil resistance and is taken from SP 24.13330.2011, Table 7.6; $\gamma_{c R}$ - is the coefficient of soil conditions under the bottom end of the pile according to SP 24.13330.2011, Paragraph 7.26.

Calculations were made using formula (1) for the load-bearing capacity $F_{d}$ for soil of various types of drill piles cutting through very soft loam with liquidity index $I_{L}=0.9$, soft loam with $I_{L}=0.6$. Pile's heel is embedded in stiff clay. The following types of drill piles are used: 1) EDT bored injection piles without any enlargements and with extensions under the foot and along the borehole; 2) $600 \mathrm{~mm}, 800 \mathrm{~mm}, 1000 \mathrm{~mm}$ auger piles made in casing pipes, under the protection of thixotropic clay, and laid by deep vibration. The results of $F_{d}$ calculations based on the diagrams shown in Fig. 1 are summarized in Table 1.

For estimation of piles bearing capacity and design loads on them, specific values are available in Table 1: is the specific load capacity $\overline{F_{d}}$ corresponding to $\overline{F_{d}}=\frac{F_{d}}{V_{c}}$, and the specific design load $\bar{N}$ corresponding to $\bar{N}=\frac{N}{V_{c}}$, where $V_{c}$ is the volume of the pile under consideration.

The most typical curves of dependence $\bar{N}$ and $\overline{F_{d}}$ on the diameter and type of piles are shown in Fig. 2. The predominance of $\bar{N}$ and $\overline{F_{d}}$ for multi-seat EDT piles is vividly traceable. It exceeds by 2.5-6.5 times the values of $\bar{N}$ and $\overline{F_{d}}$ for auger piles. At the same time, as the pile diameter increases, the functions $f\left(\varnothing, \overline{F_{d}}\right)$ and $f(\varnothing, \bar{N})$ acquire a downward linear character. 


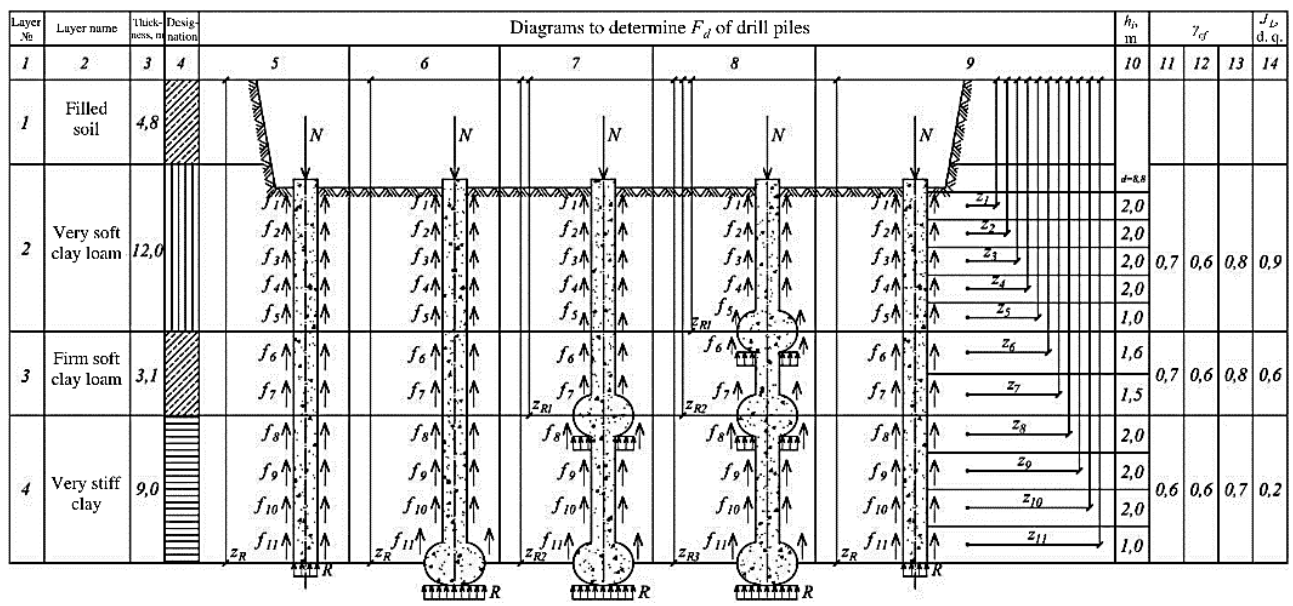

Fig. 1. Diagrams of the $F_{d}$ bearing capacity of drill piles. Column Notes: 5 -EDT bored injection pile with under-the-heel and hole extensions; 8 - EDT bored injection pile with under-heel and two extensions along the pile shaft; 9 - auger piles diameter of $600,800,1000 \mathrm{~mm} ; 11-\gamma_{s f}$ factors for drilling piles Item $3 \mathrm{a}$ (Table 7.6 SP 24.13330.2011); $12-\gamma_{s f}$ factors for drilling piles Item $3 \mathrm{~b}$ (Table 7.6 SP 24.13330.2011); $13-\gamma_{s f}$ factors for drilling piles Item 3c (Table 7.6 SP 24.13330.2011).

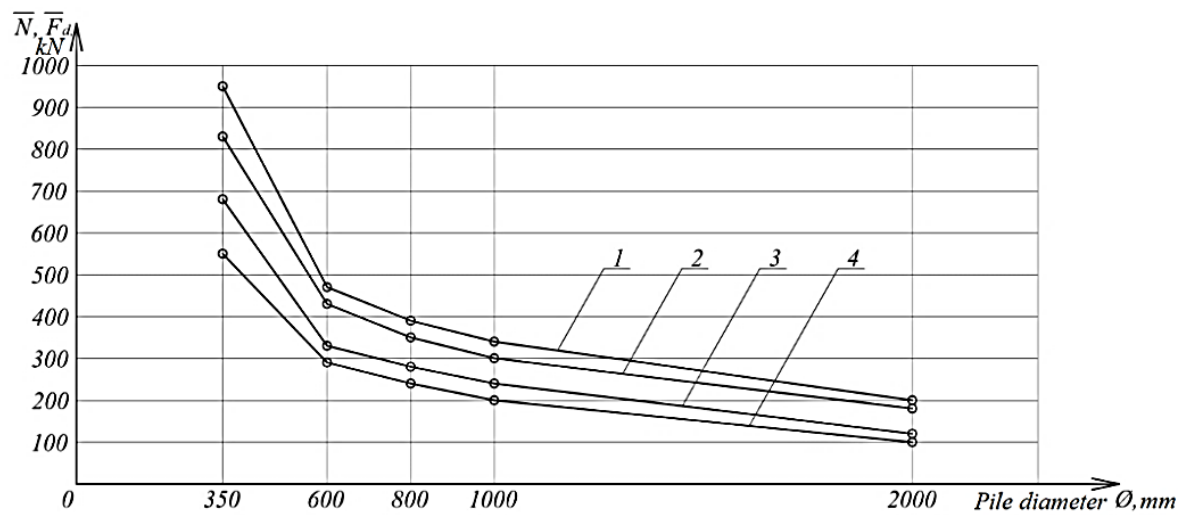

Fig 2. Dependency diagrams $f(\varnothing, \bar{N})$ and $f\left(\varnothing, \overline{F_{d}}\right)$, where $f\left(\varnothing, \overline{F_{d}}\right)$ - specific load capacity $[\mathrm{kN}], \bar{N}$ specific load $[\mathrm{kN}] ; 1$ and 2 - graphs $f\left(\varnothing, \overline{\mathrm{F}_{\mathrm{d}}}\right) ; 3$ and 4 - graphs $f(\varnothing, \overline{\mathrm{N}})$. Notes: 350 is the diameter of the EDT pile, [mm]; 600, 800, 1000, 2000 - diameter of auger piles [mm]. 
Table 1. Determination of the carrying capacity of drill piles on the ground.

\begin{tabular}{|c|c|c|c|c|c|c|c|c|}
\hline № & Pile type & Position & $\begin{array}{l}\text { Effective } \\
\text { load, } \mathrm{kN}\end{array}$ & $\begin{array}{c}\text { Assumed } \\
\text { load }\end{array}$ & Note & $\begin{array}{c}\text { Pile } \\
\text { volume, } \\
\mathrm{m}^{3}\end{array}$ & \begin{tabular}{|l} 
Specific \\
load \\
capacity, \\
$\mathrm{kN} / \mathrm{m}^{3}$
\end{tabular} & $\begin{array}{l}\text { Specific } \\
\text { design } \\
\text { load, } \\
\mathrm{kN} / \mathrm{m}^{3}\end{array}$ \\
\hline 1 & 2 & 3 & 4 & 5 & 6 & 7 & 8 & 9 \\
\hline \multirow{3}{*}{1} & \multirow{3}{*}{$\begin{array}{c}\text { Bored pile } \\
600 \text { dia } \\
A=0.2826 \\
\mathrm{~m}^{2}\end{array}$} & 1 & 2330.0 & 1665.0 & \multirow{12}{*}{$\begin{array}{c}\text { Uncased- } \\
\text { pedestal pile }\end{array}$} & 5.6 & 416.0 & 297.3 \\
\hline & & 2 & 2300.0 & 1640.0 & & 5.6 & 410.7 & 293.0 \\
\hline & & 3 & 2465.0 & 1760.0 & & 5.6 & 440.2 & 314.3 \\
\hline \multirow{3}{*}{2} & \multirow{3}{*}{$\begin{array}{c}\text { Bored pile } \\
800 \text { dia } \\
\mathrm{A}=0.50 \\
\mathrm{~m}^{2}\end{array}$} & 1 & 3760.0 & 2685.0 & & 10.0 & 376.0 & 268.5 \\
\hline & & 2 & 3725.0 & 2660.0 & & 10.0 & 372.5 & 266.0 \\
\hline & & 3 & 3935.0 & 2810.0 & & 10.0 & 393.5 & 281.0 \\
\hline \multirow{3}{*}{3} & \multirow{3}{*}{$\begin{array}{c}\text { Bored pile } \\
1000 \text { dia } \\
\mathrm{A}=0.785 \\
\mathrm{~m}^{2}\end{array}$} & 1 & 5540.0 & 3960.0 & & 15.7 & 352.9 & 252.2 \\
\hline & & 2 & 5500.0 & 3930.0 & & 15.7 & 350.3 & 250.3 \\
\hline & & 3 & 5770.0 & 4120.0 & & 15.7 & 367.5 & 263.4 \\
\hline \multirow{3}{*}{4} & \multirow{3}{*}{$\begin{array}{c}\text { Bored pile } \\
2000 \text { dia } \\
\mathrm{A}=6.28 \\
\mathrm{~m}^{2}\end{array}$} & 1 & 19400.0 & 13860.0 & & 125.6 & 154.4 & 110.3 \\
\hline & & 2 & 19850.0 & 14180.0 & & 125.6 & 158.0 & 112.9 \\
\hline & & 3 & 19860.0 & 14200.0 & & 125.6 & 158.2 & 113.0 \\
\hline \multirow{4}{*}{5} & \multirow{4}{*}{$\begin{array}{c}\text { Screw } \\
\text { injection } \\
\text { EDT-piles } \\
350 \text { dia } \\
\mathrm{A}=0.10 \\
\mathrm{~m}^{2}\end{array}$} & 4 & 1515.0 & 1080.0 & $\begin{array}{c}\text { EDT drilling pile } \\
\text { without } \\
\text { enlargement }\end{array}$ & 2.0 & 757.5 & 540.0 \\
\hline & & 5 & 1680.0 & 1200.0 & $\begin{array}{l}\text { EDT drilling pile } \\
\text { with enlarged toe } \\
\text { base }\end{array}$ & 2.0 & 840.0 & 600.0 \\
\hline & & 6 & 1880.0 & 1340.0 & $\begin{array}{l}\text { EDT drilling pile } \\
\text { with enlarged toe } \\
\text { base and along } \\
\text { the pile shaft }\end{array}$ & 2.0 & 940.0 & 670.0 \\
\hline & & 7 & 1930.0 & 1380.0 & $\begin{array}{l}\text { EDT drilling pile } \\
\text { with enlarged toe } \\
\text { base and two } \\
\text { enlargement } \\
\text { along the pile } \\
\text { shaft }\end{array}$ & 2.0 & 965.0 & 690.0 \\
\hline
\end{tabular}

\section{Conclusions}

In view of the above, the results of long-term studies and the use of electric-discharge geotechnical technology for the arrangement of buried reinforced concrete structures and the use of real geotechnical construction testing for a long period of time made it possible to recommend it for solving the following geotechnical problems:

1.In case of strengthening of overloaded foundations; 
2.In case of strengthening of foundations of existing buildings and structures in connection with the planned increase or change of the nature of operating loads at change of the design scheme;

3. When constructing new facilities next to existing ones, building and constructing buildings in restricted conditions inside existing enterprises;

4. To correct abnormal building tilts or particular foundations;

5. For landslide protection of slopes, banks of rivers and seas;

6. To strengthen the foundations of railway embankments with unstable ballast plume;

7.For solving complex geotechnical problems in reconstruction of buildings and foundations, and also in case of capital repair;

8. During construction of new facilities in complex geotechnical conditions, as well as in the presence of overlapping weak foundation soils;

9. When constructing underground floors in baseless buildings, deepening of basement floors, which entail reinforcement of the body of existing foundations, arrangement of antifiltration curtain, and also cementation of contact layer of foundation footing with bearing layer;

10. When constructing bored injection EDT piles for strengthening foundation;

11. When constructing anti-filtration curtains;

12. For construction of reinforced concrete vents on the boundary of the prism of collapse in case of strengthening of landslide slopes in order to stabilize their deformations.

\section{References}

1. M. Korff, P. Meijers, A. Wiersma, F. Kloosterman, Mapping liquefaction based on CPT data for induced seismicity in Groningen. Earthquake Geotechnical Engineering for Protection and Development of Environment and Constructions, in Proceedings of the 7th International Conference on Earthquake Geotechnical Engineering, Rome, Italy, 3418-3425, 2019

2. F. Deckner, K. Viking, C. Guillemet, S. Hintze, Instrumentation system for ground vibration analysis during sheet pile driving, Geotechnical Testing Journal, 38, 6, 893-905 (2015) DOI: 10.1520/GTJ20140275

3. R. B. J. Brinkgerve, Plaxis: Finite Element Code for Soil and Rock Analyses, Balkema, 53-56 (2006)

4. N. Denies, A. Holeyman, Shear strength degradation of vibrated dry sand, Soil Dynamics and Earthquake Engineering, 95, 106-117 (2017) DOI: 10.1007/s10706-017-0285-x

5. H. Karol Reuben, Chemical grouting and soil stabilization (American Society of Civil Engineers, $536,2003)$

6. M. P. Moseley, Ground improvement (London, UK, 442, 2004)

7. V. A. Ilichev, R. A. Mangushev, N. S. Nikiforova, Underground exploration experience. Experience Of Development Of Russian Megacities Underground Space, Soil Mechanics and Foundation Engineering, 2, 17-20 2012

8. V. M. Ulickij, A. G. Shashkin, K. G. Shashkin, Geotechnical Support of Urban Development (Georeconstruction Publ., St. Petersburg, Russia, 551, 2010)

9. Z. G. Ter-Martirosyan, Soil mechanics (ASV, Moscow. Russia, 550, 2009)

10. S. B. Ukhov, Soil mechanics, foundations and foundations (High school, Moscow. Russia, 561, 2007)

11. V. M. Ulitsky, A. G. Shashkin, K. G. Shashkin, Geotechnical Guide (guide to bases, foundations and underground structures) (SPb., Russia, 284, 2012)

12. N. S. Sokolov, S. N. Sokolov, The use of bored injection piles when fixing slopes, in Materials of the fifth all-Russian conference on New in architecture, design construction renovation (NADCR-2005), Publishing house of the Chuvash University, Cheboksary, Russia, 292-293 (2005) 
13. N. S. Sokolov, Method for calculating the bearing capacity of bores injection piles taking into account the "foot bearings», in Materials of the 8th All-Russian (the 2nd International) conference on New in architecture, designing construction and renovation» (NADCR-2014), Publishing house of the Chuvash University, Cheboksary, Russia, 407-411 (2014)

14. N. S. Sokolov, V. M. Ryabinov, About one method of calculating the bearing capacity of bored injection EDT piles, Soil Mechanics and Foundation Engineering, 1, 10-13 (2015) 